\title{
त्री \\ Technology and basic science: the linear model of innovation
}

\author{
Marcos Barbosa de Oliveira
}

\begin{abstract}
电
ABSTRACT

The concept of the "linear model of innovation" (LMI) was introduced by authors belonging to the field of innovation studies in the middle of the 1980 s. According to the model, there is a simple sequence of steps going from basic science to innovations - an innovation being defined as an invention that is profitable. In innovation studies, the LMI is held to be assumed in Science the endless frontier (Sef), the influential report prepared by Vannevar Bush in 1945. In this paper, it is argued that: (1) the LMI was introduced with critical purposes, as part of the questioning of the conception of science and the proposals for science policies put forward in Sef; (2) at a first level of analysis, the LMI appears as a straw man, defended neither in Sef, nor anywhere else; (3) the LMI is a weapon against the importance attributed to basic science in Sef, and its defense of the financing of basic research by the state; (4) the LMI is a component of the process of commodification of science promoted by neoliberalism. The last section of the paper presents a qualified defense of basic science and basic research.
\end{abstract}

KeYwords • Linear Model of Innovation. Innovationism. Bush. Oriented research. Commodification. Neoliberalism. Serendipity.

\section{INTRODUGTION}

This paper is a fragment of a larger research project that I have been working on for some time. The project's theme is the commodification of science interpreted, from one point of view, as a facet of the rise of neoliberalism, and from another, as a set of processes, classified according to the following taxonomy:

(1) Processes in which the programme of scientific research - i.e., of the set of all projects to be undertaken - comes to be determined by the market.

(2) Processes of corporatization, understood as those which introduce principles and methods typical of capitalist private enterprises into the management of the production of scientific knowledge, at all levels. 
(3) Processes of expansion and strengthening of Intellectual Property Rights (patents and copyrights), whose establishment is necessary for the distribution of intellectual goods to be carried out in the way proper to commodities, i.e., by means of buying and selling.

Each of those categories corresponds to a dimension of the global process of commodification of science. The project is divided into three parts, one for each dimension. The work on the first part is the most advanced, and partial results have already been presented in the article "On the commodification of science: the programmatic dimension" (Oliveira, 2013a; 2013b). The present paper is a complement to that article; its aim is to develop a deeper account of the relationships between basic science and technology, by means of a study of the so called Linear Model of Innovation (LMI).

\section{The LMI AS A GRITICAL GONGEPT IN INNOVATION STUDIES}

The LMI first appeared in the 1980s, and has become since then one of the key concepts of the field known as "innovation studies" (or "innovation theory"). The father of innovation studies was the British economist Christopher Freeman, who also promoted the use of the term "innovation" with the sense - more restricted than the one found in dictionaries - of a profitable invention, an invention which is capable of being adopted by a firm, by helping to maximize its profits. As I try to show in the aforementioned article, the concept of innovation, so defined, is the core of innovationism "innovationism" being the name given to the movement aimed at establishing the production of innovations as the primary end of scientific research. Since the system that determines what is and what is not profitable is the market, innovationism tends to place in its hands the programme of scientific research. Innovationism is the main neoliberal strategy to promote the commodification of science in the programmatic dimension.

Given its roots in Innovation Studies, the LMI can be conveniently characterized by quoting from a volume very representative of that field, The Oxford handbook of innovation (cf. Fagerberg, Mowery \& Nelson, 2005). In its first chapter, authored by Jan Fagerberg, there is a box called "What innovation is not", where one reads:

Sometimes it is easier to characterize a complex phenomenon by clearly pointing out what it is NOT. Stephen Kline and Nathan Rosenberg did exactly this when they, in an influential paper from 1986, used the concept "the linear model" to characterize a widespread but in their view erroneous interpretation of innovation. 
Basically, "the linear model" is based on the assumption that innovation is applied science. It is "linear" because there is a well-defined set of stages that innovations are assumed to go through. Research (science) comes first, then development, and finally production and marketing. Since research comes first, it is easy to think of this as the critical element. Hence, this perspective, which is often associated with Vannevar Bush's programmatic statements on the organization of US research systems (Bush, 1945), is well suited to defend the interests of researchers and scientists and the organizations in which they work (Fagerberg, 2005 , p. 8).

In the last paragraph of the box, Fagerberg presents Kline \& Rosenberg's two main criticisms of the LMI, to wit, that it overestimates the importance of science's role in the production of innovations, and that it is too simplistic, ignoring the many feedback loops that occur between different stages of the process. As an alternative to the LMI, the authors propose the chain-linked model - a very complex structure, with plenty of feedback loops.

Kline \& Rosenberg's article, as Fagerberg remarks, was very influential, and soon after its publication, its main theses became a commonplace in the literature of Innovation Studies, repeatedly asserted, but almost always as a dogma, a truth so well established that there is no need to spell out the arguments initially presented in its defense. Already in 1991, Rosenberg treats the question as closed, in an article whose first paragraph is:

Everybody knows that the LMI is dead. The model represented the innovation process as one in which technological change was closely dependent upon, and generated by, prior scientific research. It was a model that, however flattering it may have been to the scientist and the academic, was economically naive and simplistic in extreme. It has been accorded numerous decent burials, and I do not intend to resurrect it only to arrange for it to be interred once again (Rosenberg, 1991, p. 331).

In 1996, Christopher Freeman himself, questioning to a certain degree such unanimity, wrote:

No model of the innovative process has been more frequently attacked and demolished than the so-called "linear model of innovation" (...) At one time it was almost impossible to read a book or an article on technology policy or technological forecasting that did not begin or end with such a polemic" (Freeman, 1996, p. 27). 
Considering the sort of innovations required to deal with environmental problems caused by economic activities, Freeman comes to the conclusion, expressed in the final sentence of his article, that "elements of the vanquished and much derided linear model may come to the rescue of their successors." (Freeman 1996, p. 38) Freeman's article however did not have an impact on the widespread and dogmatic condemnation of the LMI present in the literature. In an article published in 2010 , that like Freeman's - had the intention to present a partial defense of the LMI, the authors explain their motivations as follows:

This paper was prompted by the increasing dissatisfaction with the current trend in the economic and social studies of science, technology and innovations, towards generalized criticism of the so-called 'linear model'. Even cursory perusal of the introductory sections of many of the papers published in the most prestigious journals in the subject (let alone working papers) shows that almost invariably they include statements such as "it is now well established that the LM is wrong (...)" (Balconi; Brusoni \& Orsenigo, 2010, p. 1).

In the same vein, Mirowsky (2011, p. 47) writes: "It has become a cliché to begin most courses on science policy and the economics of science with something called 'the linear model of innovation', only to rapidly disavow and disparage it, almost to the point of anguish".

As one can see, the LMI is a critical concept, a concept created in order to be condemned, as part of an attack on the views and policies defended in Vannevar Bush's famous report, Science, the endless frontier (Sef) (Bush, 1990 [1945]). The aim of this paper is to question what will be called the "Linear Model of Innovation thesis" ("LMI thesis", for short), namely, the thesis that attributes the model to $S e f$, and rejects it as inadequate.

\section{The LMI AS A STRAW MAN}

A crucial deficiency of the LMI thesis is its anachronism. The concept of innovation it involves is clearly the commercial one, equivalent to "profitable technological advance". With that sense, the concept only gained currency from the zos of last century, as the center piece of innovationist conceptions. In Sef the term "innovation" simply does not occur - let alone "linear model of innovation". The imputation of the LMI to Sef implicitly - and wrongly - suggests that Vannevar Bush was dealing with the same problem, namely, how to orient science to the production of profitable applications, only diverging as regards the strategy for its approach. 
The problem for Vannevar Bush and his colleagues in the scientific community was instead how to get generous funding from the state for basic science, without granting it the prerogative of deciding about the distribution of the funds received, or, in other words, without giving up its autonomy as regards the programme of scientific research. The reference to applications was necessary as a crucial element in the legitimizing argument for the concession of public funds to basic science, but for that purpose there was no need for a sophisticated model of the passage from basic to applied science: the conception of science as the ultimate source of technological advances was sufficient. Sef may include a linear (and simplistic) model of the connection between basic and applied science, but not a linear model of innovation.

Stokes (1997) is one of the authors who deny the presence of the LMI in Sef (although not interpreting the misattribution as resulting from an anachronism). In his words:

Three questions of increasing importance arise about the dynamic form of the postwar paradigm, the least important is whether the neatly linear model gives too simple an account of the flow from science to technology. An irony of the Bush legacy is that this one-dimensional graphic image is one that he himself never entertained. An engineer with unparalleled experience in the applications of science, he was keenly aware of the complex and multiple pathways that lead from scientific discoveries to technological advances - and the varied lags associated with these paths. The technological breakthroughs he helped foster during the war typically depended on knowledge from several, disparate branches of science. Nothing in Bush's report suggests that he endorsed the linear model as his own (Stokes, 1997, p. 18).

Edgerton (2004) questions the existence of the "linear model of innovation, arguing not only that the LMI does not figure in Sef, but also that nobody has ever advocated it. For him - and that is also the view adopted here - the LMI has no supporters, only critics. ${ }^{\mathbf{1}}$

A different view is adopted by Godin (2006), and deserves a comment. Godin agrees with Stokes and Edgerton as far as Sef is concerned. He says:

One would be hard-pressed, however, to find anything but a rudiment of this model [the LMI] in Bush's manifesto. Bush talked about causal links between

1 Freeman seems to share that view when he says that "Bush himself did not really believe in such a model. Long before this historians of science and technology, as well as historians more generally had recognized that the realities of the innovative process were far more complex than this simplistic view" (Freeman, 1996, p. 29). 
science (namely basic research) and socioeconomic progress, but nowhere did he develop a full-length argument based on a sequential process broken down into its elements or that suggests a mechanism whereby science translates into socioeconomic benefits (Godin, 2006, p. 640).

Concerning the generalized form of Edgerton's claim, however, Godin adopts a different view. For him, from the beginning of the $20^{\text {th }}$ century, the LMI did have supporters; and later, from the 3 os to the 5 os, the period on which the article is focused, in more sophisticated forms that involved the concept of development (as in the expression "research and development").

Two points must be made concerning that view. The first is that Godin does not consider the name used for concept of LMI to be important; for him it does not matter that those supporters did not use the expression "linear model of innovation" to designate the model they advocated. There is nonetheless a disagreement with Edgerton which is not only terminological, since Edgerton explicitly raises, and responds negatively, to the question "Did the 'Linear Model' exist by other names?" (Edgerton 2004, p. fff.). $^{\circ}$

The second point is that, for its innovationist critics, the defense of the LMI is an expression of the interests of the scientific community, as elaborated in Sef. The advocates of the LMI that Godin studies, on the other hand, are "industrialists, consultants, and business schools, seconded by economists" (Godin 2006, p. 64,0-1).

It is clear, therefore, that Godin's concept of LMI is quite different from the one prevailing in Innovation Studies, and also adopted in the present paper.

From the considerations so far, it seems that the LMI is a typical straw man - a view that nobody defends, brought into play for rhetorical purposes. It is necessary, however, to go beyond that verdict in order to understand the significance of the LMI thesis.

\section{The LMI AS AN ANTI-BASIC SGIENGE DEVIGE}

Among the views said to be present in Sef as components of the LMI, there is one which, if correctly understood, is indeed there. The view refers to the importance of basic science for the production of - according to the innovationist anachronic interpretation - innovations. To get the correct interpretation, one must replace "innovations" by "technological advances", i.e., applications of scientific knowledge which are useful, but not necessarily profitable. Although Sef includes among basic science's benefits to society its contribution to the competitiveness of private enterprises, it does 
not exclude the possibility that such benefits may reach society in ways external to the market system. Military and medical applications, among others, may be developed and implemented by state organs, without the involvement of private enterprises. ${ }^{2}$

That difference in interpretations, however, does not affect what really matters, namely, the fact that the importance attributed to basic science in Sef - which innovationists criticize as exaggerated - is a crucial component of the argument in favour of its financing by the state.

As regards the relationship between the valorization of basic science and the linearity of the LMI, we follow Stokes' interpretation, according to which the two elements go well together, but the former is not dependent on the latter for its substantiation. Thus, after denying the presence of the LMI in Sef in the quotation of the previous section, Stokes goes on to add:

Indeed, the linear model has been such an easy target that it has tended to draw fire from two other, less simplistic misconceptions imbedded in the dynamic form of the postwar model. One of these was the assumption that most or all technological innovation is ultimately rooted in science. If Bush did not subscribe to a linear image of the relationship between science and technology, he did assert that scientific discoveries are the source of technological progress, however multiple and unevenly paced the pathways between the two may be (Stokes, 1997, p. 19).

If one includes the valorization of basic science in its definition, only a part of the LMI is a straw man; and that part, one may now add, functions as a red herring by, as Stokes says, drawing fire away from more important aspects of the situation. That interpretation applies, however, more to the dogmatic way the LMI thesis came to be asserted in the tradition of Innovation Studies; in Kline \& Rosenberg's article, the issue of basic science's importance figures explicitly, in the form a vigorous attack on the claims of Sef.

The attack involves various observations aimed at lowering the status of basic science vis-à-vis technology. The most general one is that "the central process of innovation is not Science, but design" (Kline \& Rosenberg 1986, p. 286).

2 In the critique of innovationism developed in Oliveira (2013a), I resort to the concept of public interest science (contrasted with private interest science) to bring into consideration the domain of scientific research oriented by a concern with public welfare, and addressed to problems not susceptible to solution by the market system. (Krimsky 2003) Public interest science comprises research related to environmental problems of many kinds; to the risks of new technologies, particularly genetically modified organisms and nanotechnology; to the harmful consequences of the technological model of agriculture and to the development of alternative forms, like agroecology; to preventive medicine, to neglected diseases etc. 
The next step is the claim that technology contributes to the development of science in at least three ways. The first is by providing scientific empirical investigations with research equipment that is used in laboratories and in the observation of nature. The second way occurs when practical problems stimulate scientific research on certain domain. That sort of oriented research will be discussed in the next section. An instance of oriented research, which Stokes (1997) presents as an exemplary case is that of Pasteur's investigations about micro-organisms and their role in infectious and fermentation processes, motivated by the aim of dealing with many diseases in humans and animals, and improving the methods of production of vinegar, wine and beer. The third way technology contributes to science hinges not on the difficulty of tackling a practical problem, but on the success in doing it - achieved without the help of scientific knowledge. The prime example here is the well-known case of the steam engine, which played a central role in the Industrial Revolution, and gave rise to the field of thermodynamics.

Another argument of Kline \& Rosenberg's aimed at reducing the value attributed to basic science relies on the claim that many innovations are created in the absence of the theoretical knowledge on which they could be based. This claim is exemplified by the invention of the bicycle, for whose stability while in movement there existed no adequate analysis, the conclusion being that "Had the idea been true that Science is the initiating step in innovation, we would never have invented the bicycle." (Kline \& Rosenberg, 1986, p. 288)

The last of Kline \& Rosenberg's arguments to be considered is very suggestive of the motivations for the anti-basic science drive. The argument's core is found in this passage:

The two main components that affect innovation are (1) the current totality of stored human knowledge about nature and (2) the processes by which we correct and add to knowledge. The new additions and corrections to science each year that constitute current research are but a small part of the whole. And it is the whole of our knowledge about nature that we bring to bear, insofar as we can, when we confront a problem in innovation. The idea that we could do important innovation with this year's and last year's science as the only input is ludicrous when examined in any depth whatsoever (Kline \& Rosenberg, 1986, p. 287).

As one can see, the authors' anti-basic science stance does not correspond to an abstract value judgment about basic science as a whole, but rather to an attitude about the basic research that is conducted at any moment. The aim of that move is clearly to undermine the reasons put forward to justify the financing of research by the state. 


\section{The LMI Thesis AS A NEOLIBERAL COMMODIFYING DEVICE}

The most widespread conception of neoliberalism involves two propositions. 1. The state and the market are two separate spheres of social life which compete for space: the more there is of one, the less of the other. 2. Neoliberalism favors the market to the detriment of the state; one of its core principles is the doctrine of the minimal state.

According to that line of thought, since the public financing of scientific research is an action of the state, science policies which promote it cannot be characterized as neoliberal. However, in this section, it will be shown that there is actually no contradiction between the state funding of basic research and neoliberalism. The considerations to be presented allow the LMI thesis to be seen as a neoliberal commodifying device.

At a first level of analysis, neoliberalism can be identified with the principle of the excellence of the free market as a system for the organization of economic life, and social life in general. Whatever its shortcomings, neoliberals say, there is no better system, no alternative. A corollary of the principle is the proposition that the more sectors of social life are integrated into the market system, the better. Neoliberalism intensifies capitalism's propensity to turn everything into commodities.

At a second level, as Harvey (2007), Mirowski (2009) and others point out, neoliberalism's theoretical framework is not entirely coherent: it includes views that point in different directions, giving rise to tensions within the movement. The most important tension in the present context has to do with the role of the state in the economy. I will call the two poles of the tension the laissez-faire view, and the market interventionist view. Very briefly, they can be characterized as follows.

The laissez-faire view acknowledges that the state has some basic functions, including the administration of the currency, the establishment private property rights, and the maintenance of the bodies that are responsible for the use of force for national defense and law enforcement. The emphasis however is on what the state should not do: it should not meddle in the economy, by engaging in productive or commercial activities, by interfering with the functioning of the market, etc. The laissez-faire view begets the policies of privatization, reduction of Welfare State benefits, deregulation of markets, elimination of protectionist measures in international trade, etc.

The market interventionist view acknowledges that the conditions for the operation of the free market as the organizing principle in society do not come about naturally, but require the engagement of the state in several types of action, like the creation of markets for as yet non commodified categories of goods, the conversion of various forms of property rights into private property rights, the suppression of rights to the commons, the elimination of alternative (indigenous) forms of production, etc. 
(Harvey 2007, p. 2 and p. 159). The qualifying term "market" is meant to make clear that the interventions that the view refers to are those aimed at creating or maintaining the conditions for the flourishing of the market system. At least in principle, there may exist interventions by the state with different aims.

The tension associated with the two views is not exclusive to neoliberalism, being present already in classical economic liberalism. Analyzing the liberal movement in $19^{\text {th }} \mathrm{C}$ in The great transformation, Polanyi writes:

The road to the free market was opened and kept open by an enormous increase in continuous, centrally organized and controlled interventionism (Polanyi, 2001 [1944], p. 146).

Strictly, economic liberalism is the organizing principle of a society in which industry is based on the institution of a self-regulating market. True, once such a system is approximately achieved, less intervention of one type is needed. However, this is far from saying that market system and intervention are mutually exclusive terms. For as long as that system is not established, economic liberals must and will unhesitatingly call for the intervention of the state in order to establish it, and once established, in order to maintain it. The economic liberal can, therefore, without any inconsistency call upon the state to use the force of law; he can even appeal to the violent forces of civil war to set up the preconditions of a self-regulating market. In America the South appealed to the arguments of laissez faire to justify slavery; the North appealed to the intervention of arms to establish a free labor market. The accusation of interventionism on the part of liberal writers is thus an empty slogan, implying the denunciation of one and the same set of actions according to whether they happen to approve of them or not. The only principle economic liberals can maintain without inconsistency is that of the self-regulating market, whether it involves them in interventions or not (Polanyi, 2001 [1944], p. 155-6).

Polanyi's remarks apply equally well to present day neoliberalism, and suggest that the market interventionist view is not less neoliberal than the laissez-faire one: the two views may be conceived as alternative strategies toward the same goal of promoting the commodification of economic and social life. They assume different forms in different sectors of social life, and sometimes one, sometimes the other prevails.

Both the laissez-faire and the market interventionist views manifest themselves in the domain of scientific practices.

The laissez-faire view may be said to imply that - as for any other kind of goods the production of scientific knowledge should be entrusted to private enterprises, with 
no financing of scientific research by the state. ${ }^{3}$ There is however a serious problem with that prescription. In spite of the advances in the domain of Intellectual Property Rights, scientific knowledge still functions as a public good: with a few exceptions, it is not protected by patents, and copyrights do not provide income for its producers -i.e., for scientists, who nowadays, in a growing numbers of cases, have to pay to have their articles published. ${ }^{4}$ By publishing, a scientist acquires only the moral rights to his or her production; as far as the monetary value is concerned, the results of scientific research cannot be appropriated by its producers. Consequently, if the producer is a private enterprise, they cannot in principle contribute to its profits. To sum up, in the strict sense scientific research is not a profitable undertaking.

Now, if basic research should not be financed by the state, and the private sector has no interest in doing it, that would be the end of that practice. From that perspective, it is not difficult to perceive that the LMI thesis could be useful, by making that consequence acceptable. If innovations are all that matters, and basic research contributes little to the production of innovations, then there is no great harm in its demise.

Those implications do not tally with the fact that, as a rule in all countries with a significant science sector, the state continues to be the main provider of funds for the non-profitable researches performed at Universities and research institutes. However, how that concession of public funds to science is conceived and justified in neoliberal times is significantly different from how it was in the postwar period. The change is the result of a process that involves the rejection of the basic science/applied science dichotomy assumed in Sef, and can be analyzed, logically and historically, in two steps. Such analysis allows the neoliberal financing of research to be seen as a manifestation of the market interventionist view.

The first step consists in putting forward the idea of a form of research that is fundamental, in the sense that it may provide advances in scientific knowledge on a par with those of basic research, but oriented from start to a determinate field of applications. Suggestions of that nature started to be made already in the 5 os, but it was only in the zos that the notion of oriented research gathered strength, and then it was also defended under various other designations (with nuances of meaning among them): "programmatic research", "purposive basic research", "mission-oriented basic research", "oriented basic research", "strategic research" and "use-inspired basic research" (the term adopted by Stokes) (cf. Stokes, 1997, p. $5^{8 \mathrm{ff} . ;}$ Oliveira, 2013a).

3 Views of that sort were held in early 8 os by some neoliberal economists. See Mirowski (2011, p. 55) and Sharif (2006, p. $\left.75^{3}\right)$

4. On the thesis of science's public good nature, its use as an argument in favor of the financing of research by the state, and the critique leveled against it by a radical wing of neoliberals, see Mirowski, 2011, p. $56 \mathrm{ff}$. 
The second step consists in restricting oriented research projects so that they aim to produce applications that are profitable - i.e., that are innovations. That restriction is the core of innovationism, and since, as noted in the introduction, it is the market that determines what is and what is not profitable, innovationism puts in its hands the definition of the programme of scientific research. The public financing of scientific research, provided in accordance with neoliberal principles, is an action of the state that promotes commodification - in this case the commodification of science in the programmatic dimension -; it is therefore a manifestation of the market interventionist view.

At the conceptual level, both the laissez-faire and the market interventionist views concerning scientific practices imply the extinction of basic research (in the sense present in Sef of research motivated only by its intellectual interest to scientists). That prescription is of course not imposed once and for all, as if by a decree. In order to understand its mode of action, it is necessary to consider the situation at a more concrete level, taking into account the institutional arrangements involved in the financing of scientific research.

State funds are a scarce resource, objects of dispute by state organs at various levels, from the highest one, of ministries, to the level - in the domain of science of individual research projects within a speciality. At an intermediate level, there is grosso modo a limited amount of funds for financing the research carried out in public and private universities and research institutions, distributed by sponsoring agencies. At this level, the dispute is between the great areas of knowledge, which on average have different potentials for generating innovations. In a situation where innovationist policies prevail, it is clear that the areas with a high innovation potential will be favored, to the detriment of areas with null or low innovation potential.

That basic science has some innovation potential - or, in other words, that it contributes to some extent to the creation of innovations - is not denied by even the most radical innovationists. The problem is rather that such contribution is uncertain for each research project, and as a rule only takes place in the long run. One may say that the innovations whose production is posited by innovationists as the primary aim of science are applications that are not only profitable, but profitable assuredly and in the short run. In any case, basic science is one of the domains whose position is the competition for funds is weakened by innovationist policies. As I try to show in Oliveira (2013a), there are two other important domains in the same situation, namely, public interest science (cf. note 4 above) and the humanities. The detrimental impact on those areas constitutes one the of bases of the critique of innovationism presented in that article. 


\section{A DEFENSE OF BASIC SGIENGE}

A critique of the LMI thesis, as interpreted here, is not complete without some sort of defense of basic science. The defense to be put forward is only partial, and very summarily laid out. It is divided into two parts, each grounded on one of the two values traditionally attributed to science, namely: the instrumental value, of science as a source of technological applications, and the intrinsic value, of scientific knowledge as an end in itself.

As regards the instrumental value, the most important argument in favour of basic science figures with due prominence in Sef, although in an inadequate form. As mentioned in section 3, Vannevar Bush and his colleagues' aim was to obtain funds for research from the state, without giving up the autonomy of the scientific community in the determination of its research programme. The concession of public funds to scientific research is legitimized by the technological applications it gives rise to. However - in a move that might appear paradoxical at first sight - the production of predetermined technological applications should not be a criterion in decisions about the research programme. In other words, scientific research should not be conducted as oriented research.

The crucial element in the Bush's defense of basic science can be interpreted as an argument against oriented research. The key component of the argument is the Principle of Serendipity. (Oliveira 2013a) Serendipity is the faculty of making discoveries by accident, while searching for something else. (Merton \& Barber 2006) In the domain of scientific research, the idea is that the aim is the advance of scientific knowledge; what is discovered later, serendipitously, are applications of the knowledge produced. The Principle of Serendipity is an implication of that idea, namely, the proposition according to which, among basic research projects, it is possible to forecast neither which ones will in fact yield technological applications, nor the type of practical problem, if any, each one will contribute to solve. 5 As a consequence, research cannot be oriented and the determination of the programme of scientific research stays in the hands of the scientific community.

There are many examples of this type of occurrence in the history of science, like the early investigations of electrical and magnetic phenomena, later unified in electromagnetic theory, with its innumerable technological applications, very far from what had been anticipated by its pioneers; the researches on the atomic and nuclear struc-

5 In studies of serendipity in science and technology, one finds cases that occur within science, like that of Roentgen and the X rays, and within technology, like that of Teflon (cf. Roberts, 1989, chap. 21, 27). The Principle of Serendipity defined here refers only to unanticipated technological applications of scientific advances. 
ture of matter, which led to A- and $\mathrm{H}$-bombs, and to the peaceful use of nuclear energy; Frege's investigations into the foundations of mathematics, which involved the creation of symbolic logic and, along a line of development in which Turing played a crucial role, lead to digital computers. One interesting case, where the applications of an area of research - the theory of numbers - were not only not forecasted, but claimed to be non-existent, is the following. The English mathematician G. H. Hardy, much affected by the military applications of science in World War I, became a staunch supporter of pure, curiosity-driven science. In his book A mathematician's apology, he mentions a "saying attributed to Gauss, to the effect that, if mathematics is the queen of the sciences, the theory of numbers is, because of its supreme uselessness, the queen of mathematics" (Hardy, 1981 [194,0], p. 120). According to Hardy's interpretation, neither Gauss nor any other mathematician would decry or regret beneficial applications of number theory, if they existed. But - he concludes - "science works for evil as well as for good (and particularly, of course, in time of war); and both Gauss and lesser mathematicians may be justified in rejoicing that there is one science, at any rate, and that their own, whose very remoteness from ordinary human activities should keep it gentle and clean" (Hardy, 1981 [1940], p. 121). The irony of the story is not only that various applications of number theory were later found, in areas like population genetics and nuclear physics, but that one of those fields is cryptography, a crucially important tool in military communications.

In the literature of Innovation Studies, I have not found any direct contestation of the Principle of Serendipity. In their article, Kline and Rosenberg acknowledge that "new science does sometimes make possible radical innovations", and give the examples of "semiconductors, lasers, atom bombs and genetic engineering". But they do not mention the unanticipated character of those applications, and they claim that such occurrences are rare (cf. Kline \& Rosenberg, 1986, p. 293).

To my mind, the number of well documented cases of serendipity of the type at issue is sufficient to justify the investment in basic research, even from a purely instrumental point of view. However - and here we come to the inadequacy mentioned above - Bush's defense of basic science goes too far, in ruling out the possibility of oriented research. Such exclusion clearly does not follow from the number of examples of serendipitously generated applications, no matter how large it is. Incidentally, an analogous critique can be leveled against the innovationist views, for ruling out not oriented research, but research oriented to useful but not profitable applications or, in other words, for excluding public interest science.

Although in slightly different ways, the positions defended in Sef and by innovationists include an essentially positive conception of science. Science is seen as 
the motor of progress, as the provider of unaccountable benefits to humankind, as an indispensable factor for economic growth, etc. What is missing from that picture is the underside of science, which has also many aspects. Given its close association with industrial civilization, science must share the responsibility for the environmental problems which loom large on humankind's horizon. Then, as Hardy says - and there is some truth in this common sense view - science can be used for good and for evil, and it is difficult, from a heightened point of view, not to see military applications as being of the evil kind. Science is the main responsible for the nightmare of global nuclear destruction that still haunts humankind. Another aspect of the underside of science is the fact that its benefits are very unequally distributed, there being billions of people in the world who lack the most basic conditions for a minimally satisfactory life, like access to food, drinking water, etc. One may, of course, reply that such inequality is due to causes that have nothing to do with science, and therefore science should not be blamed for it. But even granting the validity of the reply, the fact remains that the failure of science - or, if one wishes, of society as a whole - to solve a basic problem like that of hunger, makes the instrumental value to be attributed to science lesser that what it would be otherwise.

The limitations of the instrumental value of science do not imply that it should be written off as a means of dealing with humankind's ills, even if it is partially responsible for them. As many activist groups critical of the way science is conducted say, science is part of the problem, but also part of the solution. In some cases-like the one of the hole in the ozone layer - even the detection of the problem cannot be done without recourse to science. This line of thought leads to the theme - which lies beyond the scope of this paper - of how to improve the ways scientific practices are conducted, in order to make it contribute more effectively to well-being of everybody.

The conclusion is that, with due reservations, the defense of basic science grounded on the Principle of Serendipity has some validity, and helps to legitimate its financing by the state. The criteria for making decisions about the proportion of resources to be granted to each type of research and, within basic science, to each area and discipline, depend on considerations regarding the intrinsic value of science, to which we now turn.

The intrinsic value of science plays an important role in the conception of science put forward in $S e f$, in the guise of scientists' motivation for engaging on research. That motivation must be restricted to pure intellectual curiosity, the desire to understand the workings of nature, to contribute to the advance of scientific knowledge for its own sake. Sef's prescription is that scientists not only need not, but also should not be concerned with applications, since - it is assumed - "applied research invariably 
drives out pure" (Bush [1945] 1990, p. 83). The autonomy of the scientific community in the determination of the programme of research is exercised in this way, i.e., by making it a function of the intrinsic value of science for the scientists.

That conception about the scientists motivations, from the point of view of science's two values, is forcefully defended, in a descriptive and normative key, by Hardy:

There are many highly respectable motives which may lead men to prosecute research, but three which are much more important than the rest. The first (without which the rest must come to nothing) is intellectual curiosity, desire to know the truth. [...] It may be fine to feel, when you have done your work, that you have added to the happiness or alleviated the sufferings of others, but that will not be why you did it. So if a mathematician, or a chemist, or even a physiologist, were to tell me that the driving force is his work had been the desire to benefit humanity, then I should not believe him (nor should I think the better of him if I did). His dominant motives have been those which I have stated, and in which, surely, there is nothing of which any decent man need be ashamed (Hardy, 1981 [194.0], p. $7^{8-9)}$.

In contrast with Aristotle's praise of knowledge as an end in itself, in modern science the value resides not so much in having knowledge, but in searching for knowledge. In other words, for Aristotle what is at stake is the intrinsic value of "scientific" (in his terms, "theoretical") knowledge, for modern scientists, the intrinsic value of research. What matters for the scientist is the challenge involved in research, which results from an impulse similar to that of mountain climbers and chess players.

In that context, i.e., without consideration of possible applications, research has value only for the researchers themselves. That value cannot therefore serve as a basis for legitimating the public financing of science. That is why Bush and his colleagues had to resort to the instrumental value of science to do the job.

From a social point of view, the conceptions both of Sef and of innovationism incorporate a purely instrumental valuation of science. They ignore a third form the intrinsic value of science may assume, which may be called the cultural value. It is present in non-scientists interested in science, the group of people that constitute the audience for scientific popularization in the form of newspaper sections, magazines, radio and TV programs, documentaries, etc. The number of people in that category is much smaller than that of art or sports lovers but still significant.

The purely instrumental view involves the presupposition that non-scientists are vulgar materialists, devoid of spiritual interests, incapable of gaining purely intellectual satisfaction from scientific knowledge. The instrumental view follows from that 
mistaken presupposition; moreover, as it becomes dominant, it tends to make the presupposition true, thereby promoting the spiritual impoverishment of mankind.

The acknowledgement of the cultural value of science as a factor in the legitimation of public financing of basic research leads to the question of criteria to be adopted for the distribution of resources. One criterion must consider the number of people capable of enjoying the intellectual satisfaction provided by a contribution to basic scientific knowledge. In deliberations about what projects to support, intrinsic value should have greater weight in the case of knowledge understandable by laymen - like that relating to the history of life on Earth, and particularly of our species, and the existence of extraterrestrial life - than in the case of abstruse conceptions comprehensible only by an extremely small number of specialists, like superstring theory, or the detection of Higgs boson (cf. Oliveira, 2013a)

\section{Conclusion}

This paper is essentially a critique of the LMI thesis, which is widespread in Innovation Studies and in some adjacent areas. Part of the critique has to do with the anachronism involved in the attribution of the LMI to Sef. The most important part however is targeted at the anti-basic science character of the thesis, from the point of view of both the instrumental and the intrinsic values of science. The paper explores also the relationship between the thesis and the commodification of science promoted by neoliberalism, thereby throwing light on deeper layers of significance of the thesis. $\$$

\section{Marcos Barbosa de Oliveira}

Philosophy Graduated Program,

Faculty of Philosophy, Letters and Human Sciences,

University of São Paulo, Brazil.

mbdolive@usp.br

\section{REFERENGES}

Balconi, M.; Brusoni, S. \& Orsenigo, L. In defense of the linear model: an essay. Research Policy, 39, p. 1$13,2010$.

Bush, V. Science, the endless frontier. Washington: National Science Foundation, 1990 [1945].

Edgerton, D. The linear model did not exist. In: Grandin, K.; Worms, S. \& Widmalm, S. (Ed.). The scienceindustrynexus: history, policy, implications. Sagamore Beach (MA): Science History Publications, 2004. p. 31-57. Available at: <https://workspace.imperial.ac.uk/humanities/Public/files/Edgerton\% 20Files/edgerton_linear_model_did_not_exist.pdf>. Accessed: 26 Aug. 2013. 
Fagerberg, J. Innovation: a guide to the literature. In: Fagerberg, J.; Mowery, D. C. \& Nelson, R. R. (Ed.). The Oxford handbook of innovation. New York: Oxford University Press, 2005. p. 1-26.

Fagerberg, J.; Mowery, D. G. \& Nelson, R. R. (Ed.). The Oxford handbook of innovation. New York: Oxford University Press, 2005.

. The greening of technology and models of innovation. Technological Forecasting and Social Change, $5^{3, \text { p. } 27-39,1996 .}$

Freeman, C. The greening of technology and models of innovaion. Technological Forecasting and Social Change, $5^{3}$, p. 27-39, 1996.

Godin, B. The linear model of innovation: the historical construction of an analytical framework. Science, Technology and Human Values, 31, 6, p. 639-67, 2006.

Grandin, K.; Worms, S. \& Widmalm, S. (Ed.). The science-industry nexus: history, policy, implications. Sagamore Beach (MA): Science History Publications, 2004.

Hardy, G. H. A mathematician's apology. Cambridge: Cambridge University Press, 1981 [194,0].

Harvey, D. A brief history of neoliberalism. Oxford: Oxford University Press, 2007.

Kline, S. J. \& Rosenberg, N. An overview of innovation. In: Landau, R. \& N. Rosenberg, N. (Ed.). The positive sum strategy: harnessing technology for economic growth. Washington: National Academy Press, 1986. p. $275^{-304}$.

KRIMSKY, S. Science in the private interest: has the lure of profits corrupted biomedical research? Oxford: Rowman \& Littlefield, 2003.

LAndau, R. \& N. Rosenberg, N. (Ed.). The positive sum strategy: harnessing technology for economic growth. Washington: National Academy Press, 1986.

Merton, R. K. \& BARber, E. The travels and adventures of serendipity: a study in sociological semantics and the sociology of science. Princeton: Princeton University Press, 2006.

Mirowski, P. Posface: defining neoliberalism. In: Mirowski, P. \& Plehwe, D. (Org.). The road from Mont Pèlerin: the making of the neoliberal thought collective. Cambridge: Harvard University Press, 2009. p. $417^{-} 55$. . Science mart: privatizing American science. Cambridge: Harvard University Press, 2011.

Mirowski, P. \& Plehwe, D. (Org.). The road from Mont Pèlerin: the making of the neoliberal thought collective. Cambridge: Harvard University Press, 2009.

Oliveira, M. B. de. On the commodification of science: the programmatic dimension. Science \& Education, 22, 10, p. 24,63-83, 2013a. Available at <http://link.spri nger.com/article/10.1007/s11191-012-94557>. Accessed: 26 Aug. 2014.

. Sobre a mercantilização da ciência: a dimensão programática. 0 comuneiro, 16, Mar. 2013b. Available at: 〈http://www.ocomuneiro.com/nrı__11_marcos barbosadeoliveira.html〉. Accessed: 26 Aug. 2014 .

PoLAnyI, K. The great transformation: the political and economic origins of our time. Boston: Beacon Press, 2001 [1944].

Rовевтs, R. M. Serendipity: accidental discoveries in science. New York: Wiley, 1989.

Rosenberg, N. Critical issues in science policy and research. Science and Public Policy, 18, 6, p. 335-4,6, 1991.

Sharif, N. Emergence and development of the National Innovation Systems concept. Research Policy, 35 , p. $745-66,2006$.

Stoкes, D. E. Pasteur's quadrant: basic science and technological innovation. Washington: Brookings Institution Press, 1997 .

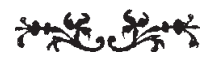

